\title{
Architecture = Building + Value: Exploring the Social Purpose of Architecture
}

\author{
Peter Wood
}

\section{Architecture and value}

I wish to begin with a contrived formula: Architecture $=$ Building + Value. That is to say that the practice of architecture is concerned with adding value to an accepted state known as 'building'. This is a simplistic but surprisingly difficult principle to disprove. It is immediately apparent that buildings, through a utilitarian distinction from sculpture, monuments, or follies and the like, have a value to us, but this value is inevitably defined within a narrow spectrum of functional servitude to human occupancy. Crudely, buildings provide security against unpredictable external factors, and they facilitate and ritualise human existence. At the level of survival, these pragmatic criteria serve firstly to protect occupants and resources from predators and adverse climatic conditions. Only after accomplishing this do they perform a secondary role, organizing controlled and centralised spheres within which ceremonies such as food preparation and consumption can accentuate social groupings and, therefore, also social and cultural developments. Both of these services can, however, in principle and practice, be more than adequately provided for without evoking disciplinary architecture (as vast areas of urban and suburban development testify). The addition I am referring to is a value over and above the survival of a corporeal frame and genetic code: one that instead celebrates being as more than simply a biological creature (or perhaps that should read a simple biological creature). This is alluded to wherever discussion of disciplinary architecture refers to the elevation of a condition sometimes described as the human spirit. This aspect of architectural value encapsulates what is widely thought of as the art of architecture, and as a state surplus to mere biological existence. However, I will not be suggesting that additional value is a worth removed from biological imperatives. Rather, I wish to show that those qualities of human activity that appear to transcend mere animalistic behaviour-and which therefore celebrate human life as removed from just biologically encoded actions-may in fact be pre-disposed tendencies that serve basic and instinctive drives for survival: animal impulses. 


\section{Architectural Elaboration}

Determining an evolution-based distinction between building and architecture begins by acknowledging the presence of art practices throughout all human society, culture, and history. As evolutionary biologist Ellen Dissanayake (1992) has observed, the universality of what we have come to call art practices can only be accounted for biologically if it satisfies an intrinsic and fundamental human need. Throughout Western history, art has been regarded as a supplement to survival-as a non-essential overloading of resources and time that adds nothing practical to a species' reproductive success. Simplistic opposition to evolutionary arguments often emphasizes art practices, since they appear to contradict basic Darwinist principles with their emphasis on biological survival rather than cultural development (Aiken, 1998). The common problem in readings of this kind is their interpretation of evolution in narrow, pragmatist terms of natural selection. They do not take into consideration the significance of emotional, social, cultural, or ritualistic criteria that are just as intrinsically a part of successful human development.

Geoffrey Miller (2001) offers an example of how an aesthetic sensibility might serve evolutionary interests. He argues that the examples we use in our efforts to distinguish ourselves from the animal kingdom are often striking for the parallels they draw with natural phenomena. ${ }^{1}$ He contends that creative and aesthetic displays are 'indicators' for reproductive choice. The importance of indicators lies in their ability to single out individuals, and help them succeed, by demonstrating their advanced intellectual ability. Human achievement throughout history was significantly linked to a creative imagination that helped advance technological fields through invention. Architecture is no exception. In evolutionary terms, the development of tools was a creative step, and may have involved aesthetic principles to identify materials most suitable to pragmatic tasks. ${ }^{2}$ In this, artists or architects were able, by making objects 'special', to demonstrate their particular ability—and thereby a particular superiority and desirability. ${ }^{3}$

Miller's assertions owe much to Dissanayake. Where his argument is limited in scope by his interest in reproductive choice, however, Dissanayake makes a greater claim for the significance of 'making special'. She emphasizes that this is the core defining feature of all art practice, and it "casts a new light on previously troublesome questions about the nature, origin, purpose, and value of art, and its place in human life" (Dissanayake, 1992: 52). 'Making special' is an example of added value. While a decorated paddle may be neither more nor less efficient at moving through water, it does offer a stronger commentary on the person who carries it, and the society that produced it. In this case, value consists in a contribution exceeding the purely utilitarian or pragmatic and, consequently, becomes quantifiable as an addition to the pre-existing state. Architecture, too, can be distinguished as a value based addition to a base condition called 'building'. It is this that architects have historically termed the 'art of building', but the usefulness of this phrase is questionable in a period when value judgments are dominated by fiscal concerns. ${ }^{4}$ Generally, the role of architecture in society can be seen as a 'making special' of buildings so that, at an urban scale, architecture signals the desirability of a city by demonstrating its
I. For example, see the discussion on the Australian bowerbird by Alphonso Lingus (2000).

2. One reason why architects have retained prominence in contemporary professional circles, despite relatively lower financial rewards, may be the way in which they are able to display their creative strengths, and therefore their suitability as stronger reproductive partners.

3. "Making things special can be done in many ways: using special materials, special forms, special decorations, special sizes, special colors, or special styles. ... From an evolutionary point of view, the fundamental challenge facing artists is to demonstrate their fitness by making something that lower-fitness competitors could not make, thus proving themselves more socially and sexually attractive." (Miller, 200I: 28I-2)

4. Current developments in architecture that seek to reduce the energy requirements in buildings are an example of 'making special' insomuch as the increase in energy performance has a tangible worth. This I see as a function of the act of building and quite apart from an art of architecture. It is arguable that any building which fails to exploit the full range of its utilitarian and serviceable requirements is, really, something less than a complete act of building (rather than a poor architectural performance). 
5. "To the unsentimental gaze of an evolutionary biologist looking for 'selective value,' elaborating is truly perplexing. What ends could it possibly accomplish? The other human capacities described here-mutuality, belonging, making meaning, and developing manual-mental competency-all clearly contribute to survival. But elaborating would appear to interfere with fitness, certainly not enhance it." (Dissanayake, 2000: 134) commitment to human advancement and progress. Such advances, however, remain firmly within a technocratic paradigm.

The key to 'making special' that I am interested in here is the achievement of a heightened emotional experience, rather than physical accommodation. That we should desire such a state may well be a consequence of the evolution of our genetic makeup, and in times of risk it is essential to our short-term survival and our long-term existence (Dissanayake, 1992: 61). Thus it is the foundation of our animalistic relationship to the world around us. At some point during our evolutionary path, we "deliberately set out to make things special or extra-ordinary, perhaps for the purpose of influencing the outcome of important events that were perceived as uncertain and troubling, requiring action beyond simple fight or flight, approach or avoidance" (Dissanayake, 1992: 51). 'Making special' is a biologically endowed need. We quite naturally exaggerate, pattern, and otherwise alter our movements or voices or words to indicate that what we are doing is set apart from ordinary states (60-1). It is to be expected that those activities most concerned with human existence also display the greatest degree of ritualised 'special-ness'. Objects and activities associated with important life events are inevitably given additional value: birth, puberty, marriage, death, hunting, warfare, and healing. These are not only perennial concerns for societies that live close to the edge of survival (Dissanayake, 1992: 34): they are also apparent in contemporary Western societies. Grant Hildebrand (1991) has made a compelling case for such 'life values' in the houses of Frank Lloyd Wright, and I would like to further his argument by contending that the threshold of distinction between architecture and building occurs at the point of divergence between two different notions of survival. Building is concerned with the survival of the immediate and singular body. Architecture, by contrast, identifies with the body as a collective, community, and especially as a congregation.

In evolutionary terms, 'special-ness' seeks to account for the way in which humans attach complex aesthetic values to essential behavioural patterns that support continued existence. The art of architecture is no more exempt from these traits than any other art practice. Studies of human evolutionary practices often suffer from an emphasis of individual fitness over social fitness. Since adding aesthetic to utilitarian value appears to offer no immediate advantages to a singular entity, whole areas of human art practice are, within such framework, dismissed as archaic, atavistic, and, ultimately, primitive. However, they can also be read in evolutionary terms as crucial markers of fitness. ${ }^{5}$ Dissanayake (1988) observes that there is no such thing as fitness in the abstract. It is by definition a response to environmental parameters and, while also concerned with reproduction, not limited to overtly practical or utilitarian aspects. In modernist architectural discourse, such markers of fitness were suppressed because of their atavistic implications.

\section{Modernism and Evolution}

The history of architecture, as written, with its theory of utilitarian origins from the hut and tumulus, and further developments in that way-the adjustment of forms to the conditions of local cir- 
cumstance; the clay of Mesopotamia, the granite of Egypt, and the marble of Greece-is rather the history of building: of 'architecture' it may be, in the sense we so often use the word, but not the Architecture which is the synthesis of the fine arts, the commune of all the crafts. (Lethaby, 1974: 1)

So begins William Lethaby in Architecture, Mysticism and Myth. Where, he asks, does the distinction between building and architecture lie? This is not a moot question but neither is it a categorical one. Lethaby's prejudice is immediately evident where he identifies the distinction between building and architecture as being like the difference between pigment and painting: building is a vehicle for architecture in a linear system that prevents architecture from ever being a vehicle for building. In his terms, buildings realise the 'manifestation and transmission' of architecture and emphasise the appeal of architecture to the intellect. This opposition between the intellectual efficacy of architecture and the corporeal expediencies of the building underlies almost all discourse on the nature of architecture in the modernist period. ${ }^{6}$

We expect architecture to engage with our lives beyond our animalistic tendencies and requirements because we see ourselves as existing in a higher domain than the animal world. All other forms of physical occupancy are, at best, mere buildings. A basic hierarchy of human edifices reflects this: shelter to structure to building and, finally, to architecture. This model is also an evolutionary one: shelter is the plane of the primitive, architecture that of the civilised, and between the two a linear progressive path upwards is emphasised. This is apparent in an architectural discourse that has privileged the primitive hut as the genesis for all architectural developments. For Vitruvius, it was the discovery of fire that led to centralised assembly and, consequently the need for new accommodations. "The men of old," he writes, "were born like the wild beasts, in woods, caves, and groves, and lived on savage fare" (Vitruvius, 1960: 38). Following Vitruvius, the classicist Laugier described the erection of the primitive hut as a direct response to the failings of the cave and the forest floor to adequately service the human desire for comfort-a state beyond survival. ${ }^{7}$ In the contemporary writing of Joseph Rykwert, finally, a fully developed theological framework to account for the primitive hut is presented. He writes:

Whether in ritual, myth or architectural speculation, the primitive hut has appeared as a paradigm of building: as a standard by which other buildings must in some way be judged, since it is from such flimsy beginnings that they spring. These huts were always situated in an idealized past. (Rykwert, 1972: 190)

'Idealized' is a euphemism for Eden. The hut may indeed be primitive but the purpose it serves is of the highest order. To distort Michel Foucault's argument on architecture and institutionalisation, we can hardly speak of God until we can point to a tangible place in which God dwells: worship and architecture become concurrent events. The primitive hut is a useful metaphor for theology, from whose perspective keeping its origins clear of pagan practices is important.
6. I will in this essay refer to writers who are not so simplistic in their structuring of architecture upon intellectual grounds, but I also hope to show that these arguments are often equally awkward in their accounts, and not without their own versions of a polemical stance.

7. "Some fallen branches in the forest are the right material for his purpose; he chooses four of the strongest, raises them upright and arranges them in a square; across their top he lays four other branches; on these he hoists from two sides yet another row of branches which, inclining towards each other, meet at their highest point. He then covers this kind of roof with leaves so closely packed that neither sun nor rain can penetrate. Thus, $\operatorname{man}$ is housed." (Laugier, 1977: 12) 


\section{Adolf Loos and Primitivism}

Adolf Loos' polemical writings are the clearest (but by no means the only) example of a modernist rhetoric that defines human progress as a movement away from an atavistic state. Loos finds evidence of the risk of regression in the ornamentation practices of 'primitive' peoples. In the course of his argument, Loos claims that it is degenerate for a civilised person to dabble in ornamentation, but perfectly permissible for a Papuan to do so

8. "One of the strangest characteristics of criminals is the tendency to express their ideas pictorially. While in prison, Troppmann painted the scene of his misdeed, for the purpose of showing that it had been committed by others. We have already mentioned the rude illustrations engraved by the murderer Cavaglia on his pitcher, representing his crime, imprisonment, and suicide. Books, crockery, guns, all the utensils criminals have in constant use, serve as a canvas on which to portray their exploits. From pictogram it is but an easy step to hieroglyphics like those used by ancient peoples. The hieroglyphics of criminals are closely allied to their slang, of which in fact they are only a pictorial representation, and, although largely inspired by the necessity for secrecy, show, in addition, evident atavistic tendencies." (Lombroso, 1911: 43)

9. Massimo Cacciari, on what he calls Loos' anti-ornament 'ethic', writes: "The concept of ornament in Loos hence goes well beyond the facade-it boils down to a concern for the ends of construction, production, and communication. For Loos, as for all the other 'great Viennese masters of language,' ornament is every word that goes beyond the conditions of its meaning, beyond the formal laws of its grammar and syntax, beyond the limits of its function." (Cacciari, 1993: 104)

10. In Loos' most notorious diatribe on ornament, it is possible to exchange the term 'Papuan' with 'pagan' and leave the intention, and syntax, completely intact. because the child-like ignorance of primitivism prevents him from acting immorally. He writes: "... the evolution of culture is synonymous with the removal of ornamentation from objects of everyday use" (Loos, 1998: 167).

His stance needs to be understood within a general context of positivist Darwinism. In particular, Loos was influenced by the Italian proto-criminologist Cesare Lombroso, who had a strong Social Darwinist orientation. Central to Lombroso's position on criminal development was the premise that some men are closer to their primitive ancestors than others, which led him to develop a scientific methodology in order to identify, through physiological data, individuals capable of aberrant social behaviour. Abnormally sized hands, bad dentition, and a pre-disposition to express oneself pictorially-especially through tattoos-are all identified by Lombroso as atavistic traits found in those predisposed to a life of crime. His position is surprisingly non-judgmental: in contemporary society, criminals are modern primitive beings who cannot control their regressive biological tendencies, such as laziness and weak-consciousness. The criminal is "a relic of a vanished race" (Lombroso-Ferrero, 1911: 135). In his interpretation of Lombroso's work Loos highlighted a relationship between primitivism and ornament, especially criminality and tattooing, while avoiding the complexities of pictographic meaning in tattooing that Lombroso found so interesting. ${ }^{8}$ The result was a simplistic and ethnocentric argument in which Loos attacked ornament as a degenerate expression of production threatening modern life with its atavistic tendencies. He wrote in 1908 that "modern man finds a face more beautiful without tattoos than with, even if the tattoos are by Michelangelo himself. And he feels just the same about bedside tables" (Loos, 1998: 165). ${ }^{9}$ For Loos, tattoos are emblematic of an atavistic corruption affecting modern life. Anything exceeding the clarity of immediate functioning represents a dangerous deterioration of cultural progress (Cacciari, 1993: 104).

It is important to emphasize that Loos' argument depends upon evolutionary principles, even as it constructs a notion of spatiality aligned with the tenets of Christian faith (Ewen, 1988)..$^{10}$ Loos' position reflects a much wider conflict between positivistic science and the prevailing European theological belief systems of the period: for the Jesuit Laugier, the primitive hut already would have represented a metaphorical dilemma. Within a theological model of creationism, the primitive hut is cast as a place of worship - the first House of God.

The primitive hut is a pivotal moment in the development of modernist principles of utility and function, but these doctrines were in conflict with popular ideologies of the period, and held in a tension similar to that between scientific rationalism and Christian theology of the Enlightenment period. It was due to the prevailing influence of this friction that ornamental additions to buildings were seen as serving no purpose other than to identify atavistic (read pagan) tendencies. 


\section{Burke, art, and the Gothic cathedral}

At this point I would like to turn to a basic definition of 'art' within evolutionary arguments to explore the theme of the 'art of architecture'. All art, states Nancy Aiken, turns on a biological response to ethnological releasers (Aiken, 1998). A 'releaser' is another type of environmental trigger that, quite literally, releases an emotional and, therefore, a behavioural response. As noted before, the most powerful of these releases are those linked to our survival reflexes, and especially the fight/flight/freeze responses. 'Art', by this definition, can be found in any cultural artefact or event that is able to activate a range of our primary reflexes, but outside of the parameters of actual physical risk. 'Art' is an activator of behavioural patterns so deeply seated in our biological makeup that they should be considered innate to the human condition and not environmentally or culturally acquired. These are generally traits concerned with survival and reproduction, but one response released by art, which Aiken finds with frequency in the built world, is the quality known as 'awe'. Monumental building -in Aiken's words, the "very huge"-is awe-inspiring because it initiates an emotional release of 'magnitude'.11

This is by no means a new or even recent observation. Writing in 1757, Edmund Burke identified awe as a division of the sublime, and he, too, found it in buildings of great magnitude. Burke's writing on the sublime, often invoked in contemporary architectural discourse, is of note here for its divergence from conventional architectural treatises of its period. The degree of divergence is evident in his definition of the sublime:

Whatever is fitted in any sort to excite the ideas of pain, and danger, that is to say, whatever is in any sort terrible, or is conversant about terrible objects, or operates in a manner analogous to terror, is a source of the sublime; that is, it is productive of the strongest emotion which the mind is capable of feeling. (Burke, 1958: 39)

Burke is describing sublimity within a range of behavioural responses that humans are genetically predisposed towards and, while he gives attention to examples of the sublime taken from the Bible, there is an immediate disparity between his proto-evolutionist observations and the prevailing creationist orthodoxy of the time. It may be for this reason that Burke never draws a direct parallel between sublimity and Gothic architecture. As Boulton had observed before, Gothic architecture displays all the qualities necessary to activate sublimity: magnitude, apparent disorder, expressions of immense energy, the gloom of the interior, and in particular the profusion of detail and suggestions of infinity through ornamental traceries (Burke, 1958: 76). The creation of artificial infinity arises, said Burke, from the uniform succession of great parts. Systematically repeating a single sound is one example, as predictable repetition creates an expectation that then organizes a frame of reference for unpredictable change, however subtle. The optical reverberations caused by a uniform colonnade moving through perspectival space is another, but it pales in comparison to the profusion of succession and uniformity that can be provided for in ornamental detailing. For Burke, ornament is the site of infinity in architecture. As our eyes fail in their ability to comprehend the movement and variability found in a complex ornamental system, an illusion of infinity is achieved, and with it
II. "Another possible releaser used in art, but which I found little about in the literature, is monumentality. Something very huge, such as the Sears Tower, the Egyptian pyramids, the Easter Island faces, and the Sistine ceiling, is awe inspiring." (Aiken, 1998: 137) 
a reflection on our own insignificance is evoked. Repetition is the simplest articulation of additional value. Whereas one curlicue is unintelligible, an ordered series proves deliberation, control, and emphasis, even as it disappears into the abstract infinity of the composition (Dissanayake, 1992: 84).

It is tempting to read 'infinity' as 'eternity' but this would miss the pagan threat at work in ornament. 'Eternity' can be thought of as a certainty of faith that exists beyond the temporality of mortal existence. We can arrive at eternity. Infinity is the converse. Infinity does not include 'ourselves' but marks out instead a concept of 'self' as nonexistent. This is why it is such a powerful releaser of sublime effect, and also why it challenges architectural thought. Where Burke says "it appears very clearly to me, that the human figure never supplied the architect with any of his ideas" (Burke, 1958: 100), he is dismissing anthropomorphism as a standard of theologised aesthetic beauty. He replaces it with emotive psychology, which treats human existence as a responsive animal behaviour.

\section{Creationism versus Evolution}

The processes of evolutionary selection take hundreds of generations. Despite its fervent conviction, modernist ideology cannot undo genetically encoded behaviour or preferences. What works best for human development is not decided by zealots and evangelical movements but is determined, to paraphrase Donald Symons (1992), in the crucible of evolutional time. I believe it is this same crucible where we can begin to fully separate architecture from building. It has been observed that the central evolutionary problem is not survival per se, "but design for survival" (Williams in Symons, 1992: 111). What distinguishes the human animal from all others is what Symons calls our "special problem-solving machinery." However, what we denote today as the 'modern' period of architectural development took place within societies with strong Christian ideals that held creationism central to human endeavour. In this context, all profane tendencies would be viewed at least with suspicion, at worst as blasphemy. While there may have been a Newtonian death of God in the sciences, the arts, and especially architecture, continued to uphold Christian values.

The builders of the great Gothic cathedrals still saw no paradox in emotionally manipulating a devout brethren with genetically determined releasers, and thereby demonstrated an architectural commitment to encouraging faith with fear. The breakdown in this successfully co-dependent relationship takes place when Pugin identifies the 'true principles of Christian architecture'. He provides his two rules for design: firstly, that there should be no features about a building which are not necessary for convenience, construction, or propriety; secondly, that all ornament should consist of enrichment of the essential construction of the building (Pugin, 1853: 2-3). In this way, he locates the primary condition of value in the action of building. This is, in its essence, the origin of Loos' anti-ornament fervour. But where Loos condemns ornament outright as an expression of latent primitive tendencies, for Pugin the true purpose of denouncing ornament is a profoundly pious declaration of the faith which architecture must serve. He writes: 
The finest temple of the Greeks is constructed on the same principle as a large wooden cabin. As illustrations of history they are extremely valuable; but as for their being held up as the standard of architectural excellence, and the types from which our present buildings are to be formed, it is a monstrous absurdity, which has originated in the blind admiration of modern times for every thing Pagan, to the prejudice and overthrow of Christian art and propriety. (Pugin, 1853: 3)

Both Pugin and Loos refuse the significance of ornament as an additional value to the value of building, and both condemn its use, although to differing degrees. The vital difference here is the debt of service. Loos holds ornament accountable as representative of architecture in decline, and its removal constitutes for him the cultural progress of buildings into a new age. By contrast, Pugin's rejection of ornament is formed inside his Christian beliefs. For Pugin, ornament in building means the ornament of pagan antiquity and to use it in a Christian context is not just atavistic, but heretical. It should be remembered that while ornament is only one expression of atavistic added value, it is the one that has dominated contemporary thought. I suggest that the reason for this dominance is the deep, unresolved conflict between creationism and evolution that the ornamental makes apparent to the external world. Other forms of additional value, such as sublimity, are emotional releasers that act inwardly and thus are less confrontational to absolute belief systems.

"When you boil it all down," says Dissanayake, "the social purpose of art [is] the creation of mutuality, the passage from feeling into shared meaning" (2000: 204). As a species, human beings across all cultures universally display the same set of needs. We need to belong to a social group, we need to find and make meaning, and we need to elaborate these meanings as a way to express their vital importance. ${ }^{12}$ Congregational worship is a profound union of these needs as people are brought together by a common belief system, with rituals and iconography that is specifically designed to provide meaning. Architecture is the perfect tool for organizing, focusing, and delivering these rituals. Elaborating on ceremonial meaning-which is to say, providing additional value-is what architecture does well. Architecture is an enhancement of where the everyday is transformed into the sublime. ${ }^{13}$

But visible atavism - be it in the form of classical ornament, repetition, or archaic architectural elements such as the gable-is not merely a reference to other times. It simultaneously denounces contemporary societies who do not have the moral, ethical, or spiritual standards that are being evoked. Unfortunately, the absolute nature of the opposition between creationism and evolution has constructed an impenetrable wall that prevents shared thought over added value. This is not to say that architects do not consciously manipulate physiological or psychological responses to the environments they design - they do-but these qualities are not thought of as 'added' in a manner that conveys architectural integrity. Until we acknowledge animal impulses in our architectural practices, uncertainty over the difference between architecture and building will remain.
12. "My thesis begins with the assumption that it is in the inborn capacity and need for (i) mutuality between mother and infant (the prototype for intimacy or love) that four other essential human capacities and psychological imperatives are enfolded or embedded and gradually, in their time, emerge. Mother-infant mutuality contains and influences the capacities for (2) belonging to (and acceptance by) a social group, (3) finding and making meaning, (4) acquiring a sense of competence through handling and making, and (5) elaborating these meanings and competencies as a way of expressing or acknowledging their vital importance." (Dissanayake, 2000: 8)

13. "Enhancement of space is achieved additionally when, within humanly shaped or elaborated space, the normal everyday arrangement of people in that space is itself altered for ceremonial purpose. Women and men may be spatially separated; performers or initiates may occupy a stage or arena apart from onlookers; some people may be excluded from the proceedings altogether. Dances usually require that individuals form rows, circles, or other regular configurations in space." (Dissanayake, 1992: 113) 


\section{References}

Aiken, N. E. (1998). The biological origins of art. London: Praeger.

Burke, E. (1958). A philosophical inquiry into the origin of our ideas of the sublime and beautiful. London: Routledge \& Kegan Paul Limited.

Cacciari, M. (1993). Architecture and nihilism: On the philosophy of modern architecture (S. Sartarelli, Trans.). New Haven and London: Yale University Press.

Dissanayake, E. (1988). What is art for? Seattle and London: University of Washington Press.

Dissanayake, E. (1992). Homo aestheticus: Where art comes from and why. Seattle and London: University of Washington Press.

Dissanayake, E. (2000). Art and intimacy: How the arts began. Seattle and London: University of Washington Press.

Ewen, S. (1988). All consuming images: The politics of style in contemporary style. New York: Basic Books.

Hildebrand, G. (1991). The Wright space: Pattern and meaning in Frank Lloyd Wright's houses. Seattle: University of Washington Press.

Laugier, M.-A. (1977). An essay on architecture (W. \&. A. Herrmann, Trans.). Los Angeles: Hennessey \& Ingalls, Inc.

Lethaby, W. R. (1974-1891). Architecture, mysticism, and myth. London: The Architectural Press Ltd.

Lingus, A. (2000). Quadrille. Performance Research, 5 (2), 1-10

Lombroso-Ferrero, G. (1911). Criminal man according to the classification of Cesare Lombroso (1972 ed.). Monclair, New Jersey: Patterson Smith.

Loos, A. (1998). Ornament and crime: Selected essays (M. Mitchell, Trans.). Riverside, California: Ariadne Press.

Miller, G. (2001). The mating mind: How sexual choice shaped the evolution of human nature. London: Random House.

Pugin, A. W. (1853). The true principles of pointed architecture or Christian architecture. London: Henry G. Bohn.

Rykwert, J. (1972). On Adam's house in Paradise: The idea of the primitive hut in architectural history. New York: The Museum of Modern Art.

Symons, D. (1992). On the Use and Misuse of Darwinism in the Study of Human Behaviour. In J. H. Barkow \& L. Cosmodes \& J. Tooby (Eds.), The adapted mind: Evolutionary psychology and the generation of culture (137-159). New York, Oxford: Oxford University Press.

Vitruvius (1960). The ten books of architecture (M. H. Morgan, Trans.). New York: Dover Publications, Inc. 